Florida International University

FIU Digital Commons

FIU Electronic Theses and Dissertations

University Graduate School

3-29-2019

\title{
No Man's Land: Critical Disability and Exile in Modernist Literature
}

Danny Fernandez

dfern171@fiu.edu

Follow this and additional works at: https://digitalcommons.fiu.edu/etd

Part of the American Literature Commons, Comparative Literature Commons, Epistemology

Commons, Feminist, Gender, and Sexuality Studies Commons, History of Gender Commons, and the

Rhetoric Commons

\section{Recommended Citation}

Fernandez, Danny, "No Man's Land: Critical Disability and Exile in Modernist Literature" (2019). FIU Electronic Theses and Dissertations. 4006.

https://digitalcommons.fiu.edu/etd/4006

This work is brought to you for free and open access by the University Graduate School at FIU Digital Commons. It has been accepted for inclusion in FIU Electronic Theses and Dissertations by an authorized administrator of FIU Digital Commons. For more information, please contact dcc@fiu.edu. 


\title{
FLORIDA INTERNATIONAL UNIVERSITY \\ Miami, Florida
}

\section{NO MAN'S LAND: CRITICAL DISABILITY AND EXILE IN MODERNIST LITERATURE}

\author{
A thesis submitted in partial fulfillment \\ of the requirements for the degree of \\ MASTER OF ARTS \\ in \\ ENGLISH \\ by \\ Danny Fernandez
}

2019 
To: Dean Michael Heithaus

College of Arts, Sciences and Education

This thesis, written by Danny Fernandez, and entitled No Man's Land: An Examination of Critical Disability and Exile in Modernist Literature, having been approved in respect to style and intellectual content, is referred to you for judgment. We have read this thesis and recommend that it be approved.

\begin{tabular}{c}
\hline Michael Gillespie \\
\hline Asher Milbauer
\end{tabular}

Date of Defense: March 29, 2019

The thesis of Danny Fernandez is approved.

Dean Michael R. Heithaus
College of Arts, Sciences and Education

Andrés G. Gil Vice President for Research and Economic Development and Dean of the University Graduate School

Florida International University, 2019 


\section{DEDICATION}

This thesis is dedicated to the memory of my grandmother, Nereyda (Mima) Mendez who was diagnosed and passed away due to her battle with ALS (amyotrophic lateral sclerosis), a disease that paralyzed all of her bodily function but never her spirit. And to my friend, Patricia Middleton, who to this day has roused in me a determination to give a voice to the disabled person living in society. And to the people of Hialeah, for their ability to promote progress in America from the exile of their many nations. 


\section{ACKNOWLEDGMENTS}

I humbly wish to show my appreciation for my committee, Dr. Nathaniel Cadle, Dr. Asher Milbauer, and Dr. Michael Gillespie for their assistance in the development of my ideas about Modernism and exile in the 21st century. Their confidence in my vision is beyond any gratitude that I can bestow in a brief acknowledgment section. To my mother, whom I have to thank for my love of the written word and her encouragement throughout my education. Many thanks to my friends and fellow Graduate English Association e-board members, President Sherri Ahern, Vice President Ismael Santos, Treasurer Rodney Castillo, Historian Crystal Veber, and CSO Representative Amanda Estevez for their support throughout our graduate seminars, the process of developing our theses, and the development of extracurricular activities for our department and members.

To Drs. James Sutton and Mark Kelley, whom I have to thank for their inclusive pedagogical styles that I hope to one day emulate. To those who believed I had a place in the master's program at FIU, Dr. Vernon Dickson, Dr. Leslie Richardson, Dr. Jacqueline Amorim, Dr. Vanessa Sohan, and Dr. Paul Feigenbaum, I owe my successes to you. To the English Department office staff (old and new), Natasha Neckles, Cora Fernandez, Gretter Machin, Roxane Timon, and Christian Gomez, who always took to helped me and my peers with your extensive knowledge of the bureaucracy at the university level. To Dr. Ana Luszczynska who challenged me in ways that helped me grow. I thank you all tremendously for all that you have done for me throughout this process. 


\section{ABSTRACT OF THE THESIS \\ NO MAN'S LAND: CRITICAL DISABILITY AND EXILE IN MODERNIST \\ LITERATURE}

by

\section{Danny Fernandez}

Florida International University, 2019

Miami, Florida

\section{Professor Nathaniel Cadle, Major Professor}

This thesis works to synthesize literary theory into an examination of sociocultural and political factors of post-World War I Europe, as they appear in Ernest Hemingway's The Sun Also Rises and Djuna Barnes' Nightwood, that led to nationalist movements in the 1930s and the current day. These concepts are divided into three sections with the first being an introduction to the formation of signifiers among the modernist writers. The second involves a differentiation of disability from gender in the expatriate community. The third an investigation of disability among the veteran expatriates. The modernist novel, whilst assisting in the creation of nation-state identities, responds to nationalist and patriarchal determination by forming characters who are outside of the norm. 


\section{TABLE OF CONTENTS}

CHAPTER

PAGE

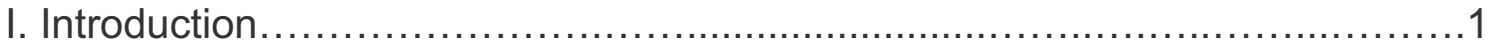

II. Gender-fluidity and Disability in Nightwood.................................12

Cultural Artifacts: Dolls and Music.......................................21

The Disability of Guido Volkbein.......................................27

III. The Exile of the Disabled Veteran in The Sun Also Rises.......................30

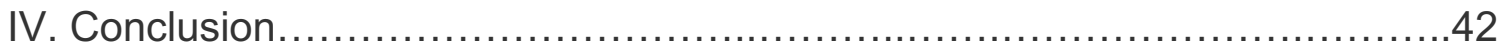

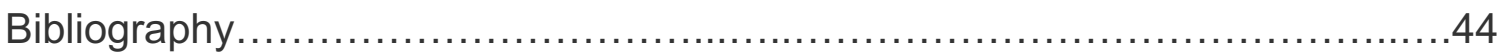




\section{Introduction}

The drawing up of 'tables' was one of the great problems of the scientific, political and economic technology of the eighteenth century... how one was to inspect men, observe their presence and absence and constitute a general and permanent register of the armed forces; how one was to distribute patients, separate them from one another, divide up the hospital space and make a systematic classification of diseases: these were all twin operations in which the two elements- distribution and analysis, supervision and intelligibility - are inextricably bound up — Michel Foucault, Discipline and Punish, 148

This research is guided by Foucault's notion of power relations with the aim of seeking to upend these systems of codes that are socially constructed in order to separate swaths of a population from their culture. Foucault's aim delineates how governing institutions at once promise order whilst exerting order as a form of control, disregarding the individuals said institution serves. My objective is to explore the association of gender and disability as they pertain to the dichotomy of nationalism and exile. The outliers in this domain are foreign bodies, bodies that are marked as other because of the socialized construction of disability. The extraction of these foreign bodies from society was done in order to create systems of labor that establish and promote the language of inclusivity and yet formulate tactics of assimilation that cause greater harm to the individual's understanding of the self. 
Ernest Hemingway in The Sun Also Rises (1926) and Djuna Barnes in Nightwood (1936) at once help create this binary and work to disrupt its creation, developing characters who are not constituted by a society, but by their culture. In my move to challenge prior readings of these two novels, I am in no way ignoring the fact that these authors and many within the modernist movement who were members of the "Lost Generation" were complicit in upholding signifiers that differentiated people due to their race, religion, and ethnicity. They do, however, show how the proliferation of what is conceived to be normal by society was formulated from a manipulated notion of history. According to Lennard Davis:

The normal- is a configuration that arises in a particular historical moment.... The novel form, that proliferator of ideology, is intricately connected with concepts of the norm. From the typicality of the central character, to the normalizing coda of endings, the nineteenth- and twentieth-century novel promulgates and disburses notions of normalcy and by extension makes of physical differences ideological differences. (12)

The disruption is the focus that allows the nation-state to transgress and situate communities into the "tabulated" numeric that gives the homogenous group greater power than the outlier, thereby leading to the conditions of exile. I am interested in reading the construction of characters that attest to their understanding of how society was creating the differences that are not true of these groups. It is my point to show that whilst both authors do set their characters into situations directed by a normative and homogenous group, they also did their part to reaffirm the status of the outliers as still having capacity. I begin here by distinguishing the categories 
of exile from Martin Tucker's list of factors that lead to its cause, which are "political, religious, cultural, personal/social, sexual, legal, and criminal" (Tucker xvii-xix). These are referential and allow a categorization of the experiences felt by individuals throughout certain points of history. These factors do not pin down each group, although each group often shares one of these concepts more than the other. However, in my later analysis of the disabled soldier and gender-fluid members of the exile communities in Europe, it is more often the case that the political and cultural factors are the referents that most apply to these characters.

Socialized models of disability, gender, and exile are all a matter of systematized groupings of people initially defined by the state and then reinforced by a homogenous group. The study of disability works in both a figurative and literal manner, the figurative here being the socialized model of disability and the literal here being the medicalized model, that is, the disability that is created to treat the body. These modes overlap in their capacity to be controlled by society. According to Tom Shakespeare, in the article "The Social Model of Disability," the social model is "a culturally and historically specific phenomenon not a universal and unchanging essence," whilst the medical model is any "approach that seeks to count the numbers of people with impairment, or to reduce the complex problems of disabled people to issues of medical prevention, cure or rehabilitation" (216). The body of the disabled is treated like a burden that must either be "cured" or "cared" for. This is language that undermines the identity of persons whose physical bodies are different from others within society. It sets a precedent, crafts the average, and leads to what is called the norm. 
This concept of the norm is marred by similar language of inclusivity expressed toward the exile. It is that of "accessibility," "impairment," and "cure." Accessibility is defined as one's capacity to take part in society, impairment works as a counter due to one's physical and/or mental state, and cure is again problematizing the capacity of a person with an impairment to assimilate so long as they remain in their condition. The medicalization of the impaired body exists to return to the average and "normal" state of being. Therefore, a socialized model is "concern[ed] with a punishment that is a correction, a therapy, a normalization, the division of the act of judgement between various authorities that are supposed to measure, assess, diagnose, cure, transform individuals - all this betrays the penetrations of the disciplinary examination into the judicial inquisition" (Foucault 227). This tool of control is a method of positioning bodies onto a continuum that prefers a sense of the body that is in "good health" and "whole."

Hence, the standardization of what is considered normal throughout time is what leads to the stratification of hierarchical positionalities of the "normal" as capable and the "abnormal" as incapacitated. Incapacitation is part of the milieu of objectification. It relegates the physical markers of bodily difference toward systemic brutalization, which limits the agency of one to take part in society and become ostracized, and in significant cases, an exile. According to Lennard Davis, in the article, "The End of Identity Politics: On Disability as an Unstable Category," "Impairment is the physical fact of lacking an arm or a leg. Disability is the social process that turns an impairment into a negative by creating barriers to access.... It relies heavily on a medical model for the diagnoses of the impairment" (265-71). 
To be diagnosed is to lose the capacity to be a multifaceted being with various ways of identifying. In that regard, both disability and exile posit positions of subjectivity in systems that are crafted to serve a master, hegemonic force. The idea of the impaired is still operating under the idea that there is a norm that is greater than a person's difference within society. The disabled person becomes a negation of the norm because of the restrictions society then imposes to limit the accessibility to services and opportunities.

As a result, the individual believes they can only be a part of society once they are cured. Eli Clare, in Exile and Pride: Disability, Queerness and Liberation, defines "that word used as a noun (the disabled or people with disabilities), an adjective (disabled people), a verb (the accident disabled her): in all its forms it means unable" (47). The term disabled is therefore used to signify that a person is physically and/or mentally powerless. The exile similarly deals with the ascription of physical and mental powerlessness, as their place in society is removed to allow the norm to proliferate with a clear enemy. The accessibility offered to a disabled person and an exile is supposed to be inclusionary, but it problematizes the capacity of a person with an impairment to take part in society and makes it so that that individual believes they can only be a part of society once they are cured.

The application of the term "normal" to people who are perceived as normative within a society (unmarked bodies) and "abnormal" to those whose bodies deviate from that norm, causes these "deviants" to lose their agency as subjects and become objects that can be manipulated by systems such as the hospital or the asylum. Deviancy is thus conveyed by a text due to these 
objectifications. The same occurs when one imagines a character as white and able-bodied regardless of whether that is the way they were described in the text. The mind fixates to the point of crafting this image and then, as David Mitchell and Shanon Snyder state in the introduction to their monograph Narrative Prosthesis: Disability and the Dependencies of Discourse, "performs a contradictory operation: a character 'stands out' as a result of an attributed blemish, but this exceptionality divorces him or her from a shared social identity" (Mitchell and Snyder 229). The goal is to challenge the symbolic representations centered on and around these experiences and then the reactions of the disabled on the basis of their physical bodies, as it is easier to find oneself exiled because of one's condition, gender, and ethnicity.

I do not want to emphasize exile as a blanket term for alienation, nor should it be limited only to the experiences of those who have endured genocide or mass deportations. ${ }^{1}$ Genocide and mass deportations, are not created out of a vacuum. These are experiences incited when the nation-state asserts that disability, gender, and ethnicity are medical disturbances that must be cured. Without the creation of the norm, the latter atrocities could never lead to the loss of human life. As I observe, the project of exile is built around the existence of disability and genderfluidity in contrast to the normative established by nationalism to view these outliers.

\footnotetext{
${ }^{1}$ Martin Tucker in Literary Exile in the Twentieth Century: An Analysis and Biographical Dictionary argues for an acute awareness for the markers of exile, stating that there are differences in the experiences of people who have been uprooted from their homes. His understanding of the concept is that an exile is a person that can neither can return home nor upon returning assimilate into this culture.
} 
In regards to power, the norm is implemented to facilitate social constructions toward the medical examination of the other. As Michel Foucault would surmise prior to these disability movements, the organization of the hospital "as an 'examining' apparatus" (185) constituted what this norm would be and how it differentiates from that which is other. The medical examination is a limiting of persons not to their status as individuals but a sum of their parts. As maintained by Foucault, "empirical and calculated methods [are] relating to the army, the school and the hospital, for controlling or correcting the operations of the body.... There was a useful body and an intelligible body.... A body is docile that may be subjected, used, transformed and improved" (136). Examination is a tool of analysis that reads a person by their impairments, establishing what Lennard Davis, calls "[the] concept of deviations or extremes. When we think of bodies, in a society where the concept of the norm is operative, then people with disabilities will be thought of as deviants" (3). The characteristic of deviance is what allows for the Foucauldian sense of penality among the individuals themselves as well as for the society that creates the transgression. Transgression involves the significations of deviance that the homogenous should work away from if they are to work within this system. As Foucault states:

The power of the Norm appears through the disciplines.... The normal is established as a principle of coercion in teaching with the introduction of a standardized education and the establishment of the écoles normales (teachers' training colleges); it is established in the effort to organize a national medical profession and a hospital system capable of operating 
general norms of health; it is established in the effort to organize a national medical profession and a hospital system capable of operating general norms of health; it is established in the standardization of industrial processes and products.... Like surveillance and with it, normalization becomes one of the great instruments of power at the end of the classical age. (184)

The process creates a mechanism of control that allows the characteristics determined by the nation to forge a common confluence among a vast group sharing spaces that were once separated by different cultural and societal heritages. It allows society to consider the body something that can be "manipulated, shaped, trained" via a "whole set of regulations and by empirical and calculated methods relating to the army, the school and the hospital for controlling or correcting the body" (Foucault 136).

In The Sun Also Rises, there is one person that is disabled and thus "emasculated" (Jake), and in Nightwood, one who is not disabled, but is branded as such (Dr. O'Connor) because of the fluidity of her gender. It is because their existence is constituted by society and the individuals within that make the characters of Dr. Matthew O'Connor and Jake Barnes exiles. According to Martin Tucker in Literary Exile in the Twentieth Century: An Analysis and Biographical Dictionary:

The distinction between exile, expatriatism, emigre, emigration-immigration, and social outlawry are clear in outline and in analytic terminology; they are rarely absolute in the experience of them. The presence of the exilic spirit 
may be detected by any number of emotional psychic characteristics; its absence may be felt (if absence is recognized as a force of presence) either in a successful assimilation in which conception of alien distinctions no longer procreates or in a consciousness of distinctions within units, a compound of identities in which divisive complexes no longer are to be gleaned. The most singular definition of exile then, is that it is a plurality of referents. (xi)

Exile is thus a transgressive act of the nation-state against these characters in order to make aspects of itself inaccessible to them. The transgression is rooted in the formation of the normative. Moreover, the expatriate is likely to deem cultural aspects inaccessible but "all cultural harassment is equally an abuse of political freedom, as no culture exists in a vacuum" (Tucker xix). In the absence of an inclusive society, the presence of the difference is felt. The exile is thrust into a state of being that at once is promoting inclusivity, but at the cost of forcing unknown customs and standards of living that are cruel in their labeling of the person. The exile cannot return to any previous state of being, much like these characters cannot find their place in either the societies of America or Europe.

Even in this attempt of return, it is a matter that yields more differences from that original state and does more to damage the self. With this in mind, consider how the medical model set about creating conversion therapy for gays and lesbians in the later twentieth and early twenty-first century or how soldiers suffering from shell-shock were thrown into asylums in the early twentieth. 
Foucault's description of leprosy at the turn of the eighteenth century foreshadows these practices:

The leper was caught up in a practice of exile-enclosure.... Individual differentiations were the constricting effects of a power that multiplied, articulated and subdivided itself; the great confinement on the one hand; the correct training on the other.... The image of the plague stand for all forms of confusion and disorder; just as the image of the leper, cut off from all human contact, underlies projects of exclusion. (199)

This is not to say that either a disabled veteran or a gender-fluid person is a 'plague' but that in a similar fashion the projects of exclusion are built around their existence among the normative. They are viewed as such by the structures and institutions set in place. In regards to power, the homogenous group can hereby contrast the principles that they associate with these groups. This "constant division between the normal and the abnormal, to which every individual is subjected" leads to medicalization: "the existence of a whole set of techniques and institutions for measuring, supervising and correcting the abnormal brings" in order to "brand him and to alter him" (Foucault 200). As Erin Carlston in Thinking Fascism: Sapphic Modernism and Fascist Modernity notes, "if we admit that fascism and culture might have something to do with each other, we are faced with the troubling problem of figuring out whether and to what degree artists or cultural artifacts can be held.... In direct causal relation to political events and particularly to the Holocaust" (12). 
Just as Carlston contends that no one clearly articulated program bred fascism, my thesis presumes that nationalism likewise relies on the notion of the norm for its affective power. Or, rather, as Mitchell and Snyder suggest, "Our notion of narrative prosthesis evolves out of this specific recognition: a narrative issues to resolve or correct a deviance marked as improper to social context" (227). Both novels I study are not void of issues that bred fascism, but reading against the negations and pointing to characters whose identities are consistently challenged, allows for a liberatory form of literary criticism. The trenches were not abandoned but expanded into the consciousness of the few who felt nothing could be done. The bodies of those caught in the crossfire had to negotiate a new understanding of this post-war world and had to pick at the insecurities of those ready to lead another assault against the systems they perceived had betrayed them.

The first chapter of this thesis distinguishes the fluidity of gender in Djuna Barnes' creation of Dr. Malcolm O'Connor, Robin Vote, and Nora Flood in Nightwood. More specifically, I read against these figures as having an ailment due to their sexuality. The second chapter focuses on how Hemingway constructs Jake Barnes as a disabled veteran not as a metaphor for emasculation or societal apathy in the post-WWI era, but as a figure who confronts the limitations that impede on his capacity to take part in the society of his fellow expatriates. 


\section{Gender-Fluidity and Disability in Nightwood}

It differentiates individuals from one another in terms of the following overall rule: that the rule be made to function as a minimal threshold, as an average to be respected or as an optimum towards which one must move. It measures in quantitative terms and hierarchizes in terms of value the abilities, the level, the 'nature' of individuals. It introduces, through this 'value-giving' measure, the constraint of a conformity that must be achieved. Lastly, it traces the limit that will define difference in relation to all other differences, the external frontier of the abnormal.... The perpetual penality that traverses all points and supervises every instant in the disciplinary institutions, compares, differentiates, hierarchizes, homogenizes, excludes. In short, it normalizes — Foucault, Discipline and Punish, 183.

The disabled and gender-fluid are both outlined as having distinct places within the consciousness of those identifying within the normative. The nationalist pursuit makes it so that one is equated with the other and reinforced by those representing the norm. I wish to begin here with the gender-fluid, but I will also discuss the disabled later in this chapter. Nationalism only sees love as a commodity, as the ultimate goal of gender is to state that the point of lovemaking is to produce heteronormative families that reproduce a later labor force. Djuna Barnes' Nightwood (1936) challenges this commodification of emotional connection by creating characters who are not defined by these heteronormative practices. Barnes creates an environment where these differences can be examined and deconstructed. In contrast to Lennard Davis' assertion that "the 
novel form is intricately connected with the [use] of a central character, to the normalizing coda of endings" (12), Barnes' novel does not follow a single linear story but jumps between time, space, and characters, as well as closing with an unresolved ending. In several chapters, the focus of the novel is on the dialogue between Dr. Malcolm O'Connor and Nora Flood, as well as O'Connor and Felix Volkbein. The book seeks to focus on Robin Vote and Nora Flood's lesbian relationship, but the brevity of the relationship lasts a single chapter, even though this time is certainly vast, as the pair owns a house decorated with items from across the several countries they have traveled.

Robin Vote is hardly ever in dialogue and is often set forth as a mythologized being. The work of the novel is to demonstrate how the nation-state attempts to create medicalized models that transform the emotional connection between people who do not identify in the male/female binary as "sick" and requiring treatment. Dr. O'Connor's female identity is called into question by all in her community of exiles when she is seen in feminine dress. She, like Robin Vote and Nora Flood, challenges the perception of gender-fluid individuals as burdens to society, in their ability to express these emotions without harassment and objectification. Doctor Malcolm O'Connor describes Nora Flood in Nightwood as "'one of those deviations by which man thinks to reconstruct himself"' (53). This statement is better situated to O'Connor, for an ex-priest in the cafe calls out to her cries of the harassment her people endure: "A sad and corrupt age" (161). The fear of gender nonconformity is equal to the fear of emotion and the complexities 
of identity in systems hoping to construct something that is "clear" and can be ascribed "value" based around what it produces for society.

Value is given to those who can best fit the norm. It is the optimal existence that manipulates how one signifies with the goal of their own labor. The medicalization of mental and physical markers as impairment are assigned value, but this is later enforced by the socialization of individuals within society. Both forms only strengthen the ideas of a nationalist state in diagnosing and controlling the status of individuals outside of the normative. Rosemarie Garland Thomson suggests in her article "Integrating Disability, Transforming Feminist Theory," that "[Disability] attenuates the cherished cultural belief that the body is the unchanging anchor of identity... undermin[ing] our fantasies of [a] stable, enduring identity in ways that may illuminate the fluidity of all identity" (345-46). As Thomson suggests, identity is a fluid state, and if the idea of disease is suggested as a negation, it similarly works to break these tenuous connections. Suggesting that this requires a "cure" or a "light" or a need to refer to a "history" escapes the consciousness of the ones being indoctrinated and brutalized by these systems, retaining the same resignation that marks what crops up on/in the bodies of others.

Whilst anyone in this hegemonic society can become disabled or be born with a disability, it is the power of one homogenous group over the other to determine these significations. The power of patriarchal conditioning asserts the communication of commodity rather than the experiences of those who have become disabled or, in turn, are labeled as such because of how the models work to impair them. This is again a challenge placed on the associations that the doctor 
makes of herself and the way her condition is equated to a disease that must be controlled. According to Deborah Tannen,

Communication is a double bind in the sense that anything we say to honor our similarity violates our difference, and anything we say to honor our difference violates our sameness.... These formulations elaborate on the tension between similarity and difference, or what Becker and Oka (1974) call 'the cline of person,' a semantic dimension they suggest may be the one most basic to language; that is, one deals with the world and the objects and people in it in terms of how close (and, I [Tannen] would add, similar) they are to oneself. (29)

The condition of woman, a gender-fluid person, or a disabled person to communicate their rationale against these systems reinforces the power that these systems hold against them. Doctor Matthew O'Connor, Nora Flood, and Robin Vote are incapacitated not because of their inability to reproach the system, but because they still have to communicate their condition in the terminology that has been manipulated around the value of labor, production, and reproduction. This is not, however, a negation of who they are, but rather a reminder that they must work doubly hard to find their subjectivity in their objectification.

Barnes further addresses the cases made against the aforementioned figures by examining patriarchal, nationalist history and the cultural artifacts used to problematize these identities in a society that promises to offer refuge. Doctor Malcolm O'Connor states, "'Man makes his history with the one hand and 'holds it up' with the other"' (90). Nationalism is forming society into a line where deviations 
from the norm do not constitute culture but aberrations. It transforms the historical and patriarchal into the ahistorical and "natural," claiming that the latter signification is truer than the complexities of the former. As Doctor Matthew O'Connor states, "We who created that the earth might be made sensible of her inhuman taste and love that the body might be so dear that even the earth should roar with it. Yet, we who are full to the gorge with misery should look well around, doubting everything seen, done, spoken, precisely because we have a word for it, and not its alchemy" (83). It is understood that nationalism removes agency and stakes a claim for their identities to be in the process of being "cured." Therefore, the doctor's statement that "No man needs curing of his individual sickness; his universal malady is what he should look to"' (32) is calling out the connections to the histories established by society and how the intention is to totalize experience in order to control people.

Barnes understood that the project of creating a norm based on these nationalist materials and histories forms exilic conditions. When one cannot find meaning in music, a doll, or culture at large, one's place is removed. Society has exempted them from participation and made what could have been a hospitable environment hostile. According to Jacques Derrida in Of Hospitality,

Paradoxical and corrupting law: it depends on this constant collusion between traditional hospitality, hospitality in the ordinary sense, and power. This collusion is also power in its finitude, which is to say the necessity, for the host, for the one who receives, of choosing, electing, filtering, selecting their invitees, visitors, or guests, those to whom they decide to grant asylum, the right of visiting, or hospitality. (55) 
At once, the goal of these materials is to promote inclusive and hospitable refuge, but they set limitations to their hospitality and therefore stand, as Derrida asserts, as an act of violence, a transgression.

According to Miriam Fuchs, "one aspect of the novel is rarely disputed, and that is its focus on suffering and the need to be healed" (125). Whilst suffering is thematic in this work, I do not agree that there is a need for the characters to be healed nor do I agree with Erin Carlston's reading of the "universal malady" the doctor discusses. Carlston in Thinking Fascism: Sapphic Modernism and Fascist Modernity states, "The doctor's monologues, conjure up scenes of amputees and shell-shock victims, the eternally incomplete.... This sense of separation and loss is figured in and recuperated by lesbianism" (72). Carlston's contention that associates disability in need of healing via lesbianism negates both signifiers, establishing a connection that affirms the norm. However, whilst Barnes is making an argument about lesbianism, she deliberates on what truly constitutes gender and the significance of the perceptions applied to gender by society. Robin Vote's child's disability and her own sexuality are consistently called into question. Robin Vote succumbing to her "ailment" in the close of novel returns the focus of the narrative to society. The disability and her exile pin the focus back onto the society that created this condition.

Carlston's reading, makes one contention similar to my own, which posits that Barnes "mock[ed] the fascist's assertion that war and violence offer the (male) individual a way to fuse with the forces of history" and "interpret all of Nightwood's statements about history as a conflict between 'feminine' values" (81). There are 
only two methods of dealing with a burden in society: one is to fully exclude the individual and separate them from their place, or to penalize their existence by creating the idea of their burdensome nature to the members who follow the command of the labor. Barnes creates the character of Dr. Matthew O' Connor with the intent of pushing against the discrimination toward gender-fluid and transgender individuals dealing with the trauma of exile. As in Nora Flood's examination, "What nation what religion, angels, priests, the dead; why should not the doctor, in the grave dilemma of his alchemy, wear his dress?"'(80). The doctor rationalizes the patterns of this language within these fields because there is a constituting of relation and hierarchies as being so diametrically opposed that it formulates distinctions between these fields that assume a "natural" signification. As Tannen states,

I note that power and solidarity are in paradoxical relation to each other. That is, although power and solidarity, closeness and distance, seem at first to be opposites, each also entails the other. Any show of solidarity necessarily entails power, that the requirement of similarity and closeness limits freedom and independence. At the same time, any show of power entails solidarity by involving participants in relation to each other. This creates a closeness that can be contrasted with the distance of individuals who have no relation to each other at all. (23)

In fact, gender is argued so strongly in this manner that rather than acknowledge Dr. Matthew O'Connor as a transgender woman she is considered a transvestite. In Dr. O'Connor's own words, "'Do you think that I, the old woman 
who lives in the closet, do not know that every child, no matter what its day, is born prehistorically and that even the wrong thought has caused the human mind incredible effort?'" (138). The assumption is that she is suffering from an ailment that causes her only to wear the vestiges of a feminine outfit. The subjectivity of Doctor O'Connor is challenged but reframed around what she notes to be of importance to society. If the doctor does not identify with the condition of her birth, then how does that harm the goal of her society? Society assumes her identity is a mental disorder that causes her to perform the femininity. Yet, it is O'Connor's participation in society that forces her to shield this identification for fear of greater penalization. Doctor Matthew O'Connor wrestles with the male gender ascribed at birth in contrast to her female identity that she is forced to hide. Djuna Barnes was focused on proving a point about the construction of masculinity as a byproduct of a society focused on maintaining a patriarchy whilst having to rationalize these sentiments to those returning from war with physical and mental disabilities.

The fluidity of gender in Barnes' creation of Dr. Matthew O'Connor, Robin Vote, and Nora Flood is insistently marred with the idea of sexuality as a disability. When the status quo is challenged by individuals who resist this urge, either because of their gender or their physical body not meeting the requirements, they are considered a burden to society. Consider how Doctor Matthew O'Connor reacts to the idea of being called a neurasthenic. The doctor asserts that Felix equated her condition equated to an illness, overly normative, as she states, "I haven't that much respect for people — the basis, by the way, of all neurasthenia"' (Barnes 33). This is in fact a reaction against the society that is signifying her being. 
Rather than acknowledging the doctor's identity, it is about what that personality imbues in contrast to the operative norm. Prior to the suggestion by Felix Volkbein that the doctor is suffering from neurasthenia, she states, "Why is it that whenever I hear music I think I'm a bride?" (33). The conditions of having neurasthenia is, as Erin Carlston notes, "the catch-all nineteenth century malady that gave rise to its own cure, psychoanalysis, [which] is the neurotic culmination of postEnlightenment Western society's obsession with individual subjectivity" (64). The experience of women in the nineteenth- and twentieth-century is often equated to "domesticity" and any deviation from this "norm" is caused by "hysterics."

In this society, a man is deemed an "earner" whose virility is found in his capacity to accomplish masculine tasks based on phallic principles. If a man shows any features opposite, he is immediately emasculated or called neurasthenic, because being less virile is the same as returning to the domestic and engaging in feminine hysterics. Hysteria and neurasthenia correlate to Sigmund Freud's research into "penis envy" and development. The threat of these gender-fluid cause them to be labeled "transgressors" of the optimal norm, but the transgression is in the development of the hierarchy. Here, again, we note the transgression of these hierarchies establishing the male gender as superior and above the female gender. Femininity and disease were then causally linked as masculinity was to good health. The woman is hence born with her disablement and lives in exile from the institution.

Exile facilitates the institutionalization of state prerogatives because it leads to a prioritizing of these hierarchies. It also sets a mistrust among individuals in 
society. Consider the ruminations of Dr. Matthew O'Connor in Nightwood: "In the average person is the peculiar that has been scuttled, and in the peculiar the ordinary that has been sunk; people always fear what requires watching" (120). The ex-priest who calls out to Dr. Malcolm O'Connor that her age is depraved and deplorable proves this to be true. Rather than make the people connected, the state takes it upon itself to handle the differences between the people. The purpose of a person is not defined by who they are but rather how they benefit the nationstate.

Cultural Artifacts: Dolls and Music

Cultural artifacts are created in order to enact normative standards and practices. Barnes uses Robin Vote and Nora Flood's doll as an example of what the patriarchy asserts is the function of the less-able woman, to create life. Barnes also uses music as another artifact, but it offers a liberatory experience. How Dr. O'Connor perceives song compared to how Felix Volkbein or Nora Flood would is wholly different. Dr. O'Connor notes a past that could have been if not for the war, Felix Volkbein sees a future that never will be, and Nora Flood imagines a present that does not exist. All three note the normative in their experience of songs, but their difference will always separate them from achieving the desire of these established norms.

Doctor Malcolm O'Connor's past is imagined as what could have been had she had not been drafted to fight in the First World War. The war effort, even with its cause of bodily damage, was necessary in the establishment of the nation-state. 
The doctor preferring to sing and deliberate on the knowledge she acquired is again challenging the status quo. Rather, her question is, what benefit does music have to the nationalist agenda and similarly how is my identity subject to the same condition? Her identification with the feminine is labeled as her disability instead of the physical impairment caused by the war. The doctor points to how the endeavor of the nation-state took the capacity of her "singing voice" when she lost her "kidney on the left side to France in the war." The doctor again restates that if she were asked to do it again then, "l'd be the girl found lurking behind the army, or up with the hill folk, all of which is to rest me a little of my knowledge, until I can get back to it.... Am I not the girl to know of what I speak?" (90). When Nora meets the doctor, she finds O'Connor wearing a gown and hairpiece. In this scene, the doctor delivers several monologues about gender and the existence of one in society. The doctor notes that the physical impairment she received serviced only to remove the musicality of her voice, but it did not remove her identification. Music, like her identity, is not something that disables her; it is the normative. This is to say, what the doctor conceded as having value was still opposite to what society believes. This imagining of a musical past conceptualizes and challenges the nationalist endeavor. Its merit as labor that benefits society is what challenges the conception of the norm because it is a form that requires emotional significance.

Baron Felix Volkbein connects to the music that he and his family are not able to take part in. The future that he imagines for his lineage is that of a patriarchal force connected to the nation-state. Felix's choice of song is that of a rigid system, the hierarchies of a lockstep and strict form. Whilst Felix himself never 
took part in the battlefields, his life, it can be argued, was one that engaged in a war against the signification that both he and his father fought against. They both fell into the same longing for a place among the ranks that are qualified as different. His relation with Robin produced a son, but it produced the final outcome of what he was always searching for. What his son is granted is what he himself never knew.

Felix called for military music, for Wacht am Rhein, for Morgenrot, for Wagner; his monocle dimmed by the head of the room, perfectly correct and drunk, trying not to look for what he had always sought, the son of a once great house; his eyes either gazing at the ceiling or lowered where his hand, on the table, struck his thumb and little finger against the wood in rhythm with the music, as if he were playing only the two important notes of an octave, the low and the high; or nodding his head and smiling at his child, as mechanical toys nod to the touch of an infant's hand, Guido pressing his own hand against his stomach where, beneath his shirt, he could feel the medallion against his flesh. (122-23)

Here, Felix and Robin's son, Guido, is capable of taking part in the cafes that would label him as an outlier who cannot take part in society. His father's responsibility for his son means that the son is demonstrably a part of these societies and given a place even with his physical ailment. Whilst he does not have access to the life of a Baron and quite possibly will not extend their familial name himself through reproduction, the desired future imagined in the music is one that would do more to continue the family's displacement. Felix, with all his assertions about his 
aristocracy, is made light of by society. He is only ever granted membership to the circus because of his difference from the norm.

Robin and Nora's relationship in regard to music imagines a present that they can never have. Robin, more than Nora, is struggling to find a space that is her own. Their home works as a space that gives credence to the outer world but also makes accessible their relationship, which would otherwise be deemed an illness. Whilst music for the doctor symbolizes the past that she can never engage with, the songs that Robin sings are defined by the nations in their use. According to Nora's observations,

Sometimes it rang clear in the songs she sang, sometimes Italian, sometimes French or German, songs of the people, debased and haunting, songs that Nora had never heard before, or that she had never heard in company with Robin. When the cadence changed, when it was repeated on a lower key, she knew that Robin was singing of a life that she herself had no part in; snatches of harmony as tell-tale as the possessions of a traveller from a foreign land; songs like a practised whore who turns away from no one but the one who loves her. Sometimes Nora would sing them after Robin, with the trepidation of a foreigner repeating words in an unknown tongue, uncertain of what they may mean. Sometimes unable to endure the melody that told so much and so little she would interrupt Robin, unseen, gave back an echo her unknown life more nearly tuned to its origin. Often the song would stop altogether, until unthinking, just as she was leaving the house, Robin would break out 
again in anticipation, changing the sound from a reminiscence to an expectation. (57)

These songs are a testament to the goal that the cultural domination has in separating Robin from society. However, it also establishes that, in song, the opposite can be true. It can work as a signifier of the exilic condition of one who would like to take part in the normative but can never return to it because of their status outside of the normative condition. This scene demonstrates how the preference for labor is a marked form of citizenship and engagement. If one is attuned to the songs of a particular nation, they can, for a time, embody that national culture. Yet, in that moment, they are signified again as the demonstrative other.

Whereas music allows for various understandings that are not exclusively held to a point, the social construction of the doll manifests in the gifting of the doll. Consider how the doctor discusses the concept of the doll that Nora gifts Robin. The doll works as yet another figure of control, another means of stimulating the reproductive urge as well as the goal of heteronormative relations. It instills labor as the final outcome, that of creation and later subjugation. It normalizes what a person should look like even as the only descriptor of gender is in its dress and not any bodily markers. The doctor states, "The last doll, given to age, is the girl who should have been a boy, and the boy who should have been a girl... The doll and the immature have something right about them, the doll because it resembles but does not contain life, and the third sex because it contains life but resembles the doll" (142). In this statement, the doctor proves that to press an identification on a 
child is the same as voiding it of its capacity to live. The doll is an object and is used as a means of setting the objectification. The doll only "speaks" because of its work to diminish the status of those whose sexuality will not produce a child but also will not fit into the doll's prescription of the norm.

This register of the doll as the physical embodiment of the norm is another way of confirming the exile of persons whose gender is not affixed by their physical being. Nora adds that "it's the effigy and the shroud; when a woman gives it to a woman, it is the life they cannot have, it is their child, sacred and profane; so when I saw that other doll' Nora could not go on. She began to cry. 'What part of monstrosity am I that I am always crying at its side!'” (142). The imparting of the doll to children and later to her lover reinforces the manipulative dominance of the nation-state and its categories of control between relations. As Tannen states in her correlative research between cultural and dominance frameworks,

It implies that those who work in the so-called "power" or "dominance" framework have corner on the market of hierarchical relations: if the two phenomena are conceptualized as mutually exclusive poles, then these who suggest that women's and men's styles can be understood in the framework of cultural difference are represented as denying that dominance exists. (9)

The disabled and gender-fluid are both outlined as having distinct places within the consciousness of those identifying within the normative. The nationalist pursuit makes it so that one is equated with the other and reinforced by those representing the norm. Barnes creates an environment where these differences 
can be examined and deconstructed. This is not to say that a person labeled with a disability cannot actually have a disability, but the work of the nation-state to create medicalized models that transform both identities into a burden on society is what can lead to the problematizing of identity and the stakes of individual identity. When one cannot find meaning in music, a doll, or culture at large, one's place is removed. Society has exempted them from participation and made what could have been a hospitable environment hostile. If one reads cultural artifacts as merely having signification to a culture, then it denies the fact that there is a method of control ascribed. Whilst the production of objects has power to affect a person's engagement, those objects are used as tools to objectify the bodies of those within society.

The Disability of Guido Volkbein

As developed further in the next chapter, my argument moves away from the socialized conception of sexuality as a disability toward that of an actual disability in the text. In Nightwood, the character of Guido Volkbein is granted accessibility that is given to a boy whose diagnosis leaves him physically different from the norm and objectified by his father. This is to say, Barnes creates this difference in her text in order to point to the difference in both experiences. When Felix and the doctor meet after Robin's desertion of the family, Felix and Robin's son Guido is labeled abnormal for being mentally deficient by society and his father. The doctor challenges this conception of value, which are descriptions applied to persons within society. Guido is a symbol of what his father hopes to 
create, in that his father before him was attempting to create a sense of nobility and status within a society that had shunned him for his Jewishness. Thus, Guido is the "sick" link that separates Felix from ever attaining that desired place within society. Yet, the doctor refutes this claim that one should aim to become a member based on their labor:

With Guido you are in the presence of the 'maladjusted.' Wait! I am not using that word in the derogatory sense at all; in fact my great virtue is that I never use the derogatory in the usual sense. Pity is an intrusion when in the presence of a person who is a new position in an old account - which is your son. You can only pity those limited to their generation. Pity is timely and dies with the person; a pitiable man is his own last tie. You have treated Guido well. (117)

O'Connor is explaining that the labor of the father for the son, that is, his ability to grant his son the same opportunity as other children, is far more important than what the father has deemed the appropriate measure. Felix could have set about searching for a mental asylum, a treatment, or any other medical institution to care for his son, but does none of that. Guido, like O'Connor, Robin, his father, and Nora, is an outlier, but he is never subjugated to the methods society would pursue to correct his disability. Prior to this remark by the doctor, Felix states, "He is not like other children, not cruel, or savage. For this very reason he is called 'strange.' A child who is mature, in the sense that his heart is mature, is always, I have observed, called deficient" (115). This is the acknowledgement by Felix that proves his own sentimental connection to what he has observed of the existence of the 
expatriates. In their express difference to the societal norm, they have been suggested deficient and have found accessibility amongst one another.

The Doctor goes on to surmise, "It may be considered 'depraved' by our generation, but our generation does not know everything.' He smiled. 'For Instance Guido; how many will realize his value? One's life is peculiarly one's own when one has invented it" (118). The individual's capacity for creating their own values, here, far outweighs the constructs of society. This reclamation of the value that one is able to ascribe to themselves is more important than the claims of reproduction and profit. The marginalized are squarely against the nationalist endeavor's pursuit and prove that even those whose minds and bodies are considered outliers are efficient in producing merit in their emotional connection to each other.

Thus, the disabled and gender-fluid are distinct categories used by the normative to mean the same thing they are not. The societal implementation of the norm make it so that the outliers can be done away with and penalized. It is in this consistent creation that often these figures can actually negotiate a way out of the reconstitution and imagine their liberation. The nationalist pursuit makes it so that one is equated with the other and reinforced by those representing the norm. 


\section{The Exile of the Disabled Veteran in The Sun Also Rises}

We must cease once and for all to describe the effects of power in negative terms: it 'excludes', It 'represses', it 'censors', it 'abstracts', it 'masks', it 'conceals'. In fact, power produces; it produces reality; it produces domains of objects and rituals of truth. The individual and the knowledge that may be gained of him belong to this production. - Foucault, Discipline and Punish, 183

In The Sun Also Rises (1926) by Ernest Hemingway, the character of Jake Barnes is created as someone capable of managing the masculine indoctrination of his society by coming to terms with his disability as a way of understanding the place he inhabits. Understanding of place is the realization that the system does not make smoke and mirrors of the patriarchy. In a sense, the state had already created an idea of what disability meant outside of the medicalized method and glossed over the fact that war would not only produce casualties but also force society to readmit members who had lost parts of their being. The socialized model is itself an oxymoron because it fails to create the outcome it promises or to prove that there is an inherent value of these contrived associations. According to Eli Clare, "community and culture burrow deep into our bones" (11). This model becomes so engrained that it becomes difficult to separate the reality of war from the fictionalized account. I reiterate that exile is not defined as a negative marker nor does it relate to censoring. In fact, in my contention, I argue that the veterans who returned from the battlefield with injuries were constructed as beings 
physically incapable and that Hemingway challenges this signification via the use of Jake Barnes.

The production of exile is not one that exists separate from society. It is the institution that produces these conditions. The vision of the body, even in its own difference, could be made to fit a cookie cutter mass. The soldier could be formed into a machine whose labor would institute the final objective of a nation, that is, to work as its own body. The soldier was the arm and legs that could enable the expansion of borders or the defense of those borders. Society had to sell this image in a way that would make the individual invest in its organization. It produced the body of the fully male soldier, exacerbating the masculinity that war itself could bring. In the attempt to formulate the body as a technology whilst producing technologies that would dismember the body, what was to be done with people returning with a break in the promises that the war would produce? It was important to figure out how to rationalize the idea of disability as inability. Thus, as Foucault states,

Disciplines; they became, thanks to them, apparatuses such that any mechanism of objectification could be used in them as an instrument of subjection, and any growth of power could give rise in them to possible branches of knowledge; it was this link, proper to the technological systems, that made possible within the disciplinary element the formation of clinical medicine, psychiatry, child psychology, educational psychology, the rationalization of labour. (224) 
The First World War promoted a closer bond to society the soldiers themselves were supposedly defending. When soldiers returned and were categorized by what the war had done to them, they felt betrayed and ostracized. The very idea of labor in relation to what the effort can cause to a person's body is at stake here. The promise of the experience to "transform doughboys into 'better men'- both physically and mentally than they could ever become in civilian life" (Kinder 59) was wholly different from the toll that war would cause and the markedly different experience once they returned from the battlefield.

The impotency experienced by Jake Barnes, a disability garnered from the battlefield, is often read as a "metaphor of the Lost Generation's disillusionment and betrayal" (Kinder 109). A somewhat problematized interpretation posits that "Jake's impotence is kind of compensation for Brett's promiscuity" (Michaels 13). While neither of Kinder's nor Michael's arguments are necessarily false, I aim to shift the reading of this text in such a way that it responds to wider discourse about what it means to be "American" in the first place. According to Martin Tucker, "our experiences reveal an amalgam of virtues and ideals, decadence and failures, and occasionally premeditated crimes against personhood and community" (xvii). Earlier discussions of the novel risk dehumanizing the experience of a disabled veteran via their reduction of that disability to a metaphor, or they conceive of masculinity and femininity as rigid markers of being that dehumanize a man and a woman.

Walter Benn Michaels, in Our America: Nativism, Modernism, and Pluralism, argues that that "version of impotence makes Jake white" and works as 
another marker for difference by asserting "white impotence" being "defined by opposition to Jewish potency" (95). I disagree with Michaels on the assumption that a bodily difference, particularly one that renders relational interaction between Jake and Brett difficult if not impossible, does not work to signify a difference that makes both Jake and Robert Cohn similar insofar as that commonality is their relation to a particular woman. This argument for their similarity in their "relations to Brett" is another form of objectification (72). In fact, making Jake's bodily injury metaphorical is another form of objectification that upholds the masculine signifier that leads to readings of Jake as emasculated. Also, if Brett is seen as only an affirmation of masculinity because of her femininity, then her promiscuity can be read as a way for her to "become" male. Again, the notion expressed by Michaels circles back to the psychoanalytical logic expounded in the previous chapter.

When attending an event in his honor, Jake recalls how the speaker notes that Jake's injury was like "giv[ing] more than his life," and it is particularly important that the speaker prefaces this with Jake being a 'foreigner, an Englishman' (any foreigner was an Englishman)" (39). The loss of Jake's penis (the signifier of his masculinity as well as the final impetus of any person in society) is more important than the fact he is alive.

The masculinity confirmed by this valor is not evident because he lost his phallus. To add insult to injury, his labor is not acknowledged by his nation-state but by that of another, and even then, his difference from their culture is evinced by his being a foreigner, an Englishman. Foucault would state, "It constitutes a body-weapon, body-tool, body-machine complex. One is as far as possible from 
those forms of subjection that demanded of the body only signs of products, forms of expression or the result of labour" (153). If the body as a tool of these productions is deficient in any of these tasks, then it becomes an outlier that breeds its own sense of shame. As Kinder notes, "disfiguring wounds to the face were especially feared, as were injuries to the abdomen, genitals, and spinal columnand not just because all were likely to result in permanent impairment. More than a lost hand or 'lame' leg, such injuries threatened soldiers' ability to live up to social codes of masculinity and sexual virility, a fate many men believed was worse than death itself" (71). The affirmation of his disfigurement by this other nation serves to mock him doubly, as not only has he "failed" the production of labor in the name of his nation, but he was "not to think about it. It was swell advice. Try and take it sometime. Try and take it.... Then all of a sudden I started to cry. Then after a while it was better and I lay in bed and listened to the heavy trams go by and way down the street, and then I went to sleep" (Hemingway 39).

With all that being said, Jake maintains a practical association with his business, his writing, and his friendships. This is not to say that Jake's value is determined by his production, but rather that his place in society is not construed as a burden. More common to those experiencing this return from the battlefield was a difficulty to find work and return to relationships that came prior to the war. According to Clare Barker and Stuart Murray in "Disabling Postcolonialism":

In communities experiencing mass disablement (due to war, disaster, industrial accident) people with disabilities often constitute a numerical majority.... Here, in a process Said would recognize only too well, the chain 
of events by which high-risk environments, poverty, and disability mutually produce and reinforce one another exemplifies the relationships of power that systematically devalue human lives. (71)

Jake is a multi-faceted character who is trying to find his place in a society that is dealing with a changing dynamic that leaves those unwilling to note their own disabilities in a state of exile. According to Eli Clare, "community and culture burrow deep into our bones" (11). Jake's ability to negotiate these attitudes is what makes him critical of the blasé attitude of his peers to the indoctrination of their society. Instead, Jake represents how this period was attributing features to people who were emerging from a shift in the dynamics of their institutions. In presenting the physical experience of a soldier returning from the battlefield of the First World War with missing physical features of his being, Hemingway can balance the effects of war on the body with the socialized conceptions of people inhabiting those bodies.

The same can be said of interpretations of Jake's impotence as a form of emasculation which constitute another form of these same conditions of dominance. According to John M. Kinder in his monograph Paying with their Bodies, "by the late eighteenth century, the soldier has become something that can be made; out of a formless clay, an inapt body, the machine required can be constructed; posture is gradually corrected; a calculated constraint runs slowly through each part of the body, mastering it, making it pliable, ready at all times, turning silently into the automatism of habit" (Kinder 135). If the body was strengthened and pushed to its strongest form, the promise and initial results of the training were true, but the effects of the training were short-lived when delving 
into the pits of the trenches, nearly choked to death by noxious gases, or blown to bits by the modern mechanisms of war. As John M. Kinder states, "disabled populations were also targets of rapidly shifting ideals of health and public respectability. At a time when physicians equated total health with physical and mental wholeness, people with disabilities were frequently diagnosed as emotionally unbalanced and sexually ambiguous" (Kinder 31). By the twentieth century, the body was becoming far less important than the technology developed for the war.

In a way, the disciplined body became its own cure to that of the average citizen. The soldier would enable the body to move outside of the restraints pursued by the political dominance that had already ascribed meaning to the subject. The answer was complicated, society had to choose either to produce the idea that the disabled veteran is outside the domain of the public or the disabled veteran is a valorized member whose return was the maxim of masculinity. PostWWI era society often flipped between both ideas depending on the damage done to the veterans body and mind. However, both ideas maintained these individuals as burdens whose return was not reproducing the cultural imagination of the soldier. The model created for dominance established a cultural connection to "a culture that associated disability with state dependency and compromised masculinity, many newly injured warriors sank into long bouts of depression, unwilling to accept their new identities as disabled men" (Kinder 70). Jake's aspirations and his bouts with depression point to his exile from the societies of Europe and the United States. He does feel a slight was done to him. The struggle 
of having the disability is not the issue, it is the fact that his prior existence made him believe that he could possess a greater status because of what he did in the war.

Even with this dynamic in place Jake goes against the nation-state, much like the doctor in Nightwood, by forming his own practice and existence within the system. Consider the popular term for the space between the trenches of the First World War. "No Man's Land" was construed as a valley of death, an escape from the disease, rot, and noxious gas into the exposed terrain that divided the two forces from one another. In a way, this warfare was much like the signifiers being applied to the body. The moment a unit was ready to fight for the final, masculine meaning was the moment that they realized how the symbolic representation of masculinity was different from the onslaught of bodily harm and physical violence. In that liminal space, bodies were constituted, examined, killed, disabled, etc. The affections that soldiers had for one another, the unity in the spirit of their camaraderie went against the purpose of their labor. "No Man's Land" was hence constituted outside of these trenches and eventually projected onto society that was reeling from this onslaught too, the veterans had formed their own culture, as Hemingway himself observed in A Moveable Feast:

I watched to notice how well they were overcoming the handicap of the loss of limbs, or at the quality of their artificial eyes and the degree of skill with which their faces had been reconstructed. There was always an almost iridescent shiny cast about the considerable reconstructed face, rather like that of a well packed ski run, and we respected these clients more than we 
did the savants or the professors, although the latter might well have done their military service too without experiencing mutilation. (74).

Bill Gorton's sense of this situation is again working to point out the inadequate assumption of his fellow compatriots. Whilst meaning to discuss society at large, as most of the audience has been privy to, he states "One group claims you're impotent" (120). In a sense, Bill agrees with this sentiment, which, when Jake responds about his impotence being an accident, causes him to shudder at the realization that he is neglecting the experience of his comrade. Bill utters the same advice offered by the speaker at commendation ceremony for Jake, that Jake must "never mention that" (120). In communicating his experience the idea of getting over the experience of disability is again reified. Bill, who experienced the same rupture on the battlefield as Jake, has to negotiate the pain that he does not understand his friend to have.

Bill Gorton excuses himself by returning to that aspect of their relation that creates the same difference they are both attempting to escape. Bill Gorton exclaims his affection and respect for Jake during their fishing trip in San Sebastian, Spain. Shortly after this moment, Bill has to deny this affection. Bill states, "I couldn't tell you that in New York. It'd mean I was a f__ (121). Even their trip together would be acknowledged as out of bad form and fall into the lens that theirs is a lost generation. In fact, these men took a negative moment like running between the trenches and watching the promises of war become a fleeting figment, and developed that space as a possibility for the capacity of relations that 
are constituted as being outside the norm. The nation-state is challenged because of its concern for this dynamic between men.

Furthermore, improvements in twentieth century medicine meant that when medics stepped onto the battlefield, the chances of wounded soldiers surviving were higher during the First World War than in any war prior. Yet, when Jake meets Count Mippipopolous, a veteran of several wars and revolutions, the idea that one can afford themselves a life even with their disability is not contrasted against Jake's own life. In the text Jake states, "The count stood up, unbuttoned his vest, and opened his shirt. He pulled up the undershirt onto his chest and stood, his chest black, and stomach muscles bulging under the light.... Below the line where his ribs stopped were two raised white welts.... Above the small of the back were the same two scars, raised as thick as a finger" (67). This body is displayed for Jake and Brett to notice, but the idea of that signification is forced outside of the closure that is imagined after a time has passed between generations. In a sense, Hemingway is gesturing how the disabled veteran in the post-WWI era is having their existence manipulated to fit the normative narrative. Count Mippipopolous's existence similar to Jake's subverts what the narrative of the time is attempting to create.

The final lines uttered by Jake Barnes offers a resigned sentiment about a society deemed complicit and apathetic in the face of the language that caused and will cause violence against a variety of minority groups within nation-states: “'Isn't it pretty to think so?'” (Hemingway 251). Language expressly made Robert Cohn, Lady Brett Ashley, and Jake Barnes entities separate from the nation of the 
United States of America and led them to immerse themselves among the European societies of France and Spain, but altogether separate in their own collective cultural enclaves of fellow English speakers from America and the British Isles. This ending has been read countless times as a mere resignation in a time marred by aimless expatriates meandering between cafes, inebriated and incapable of escaping these injustices. The ending of the novel should therefore be read as Jake's challenge to the status that was assigned to him. It disputes the necessity of reproduction and calls to task what war has created. Instead of making the results of the war the issue for why a shift in the associations happened, the war itself is to blame for making all people experience some form of exile.

Jake's wound is always assigned a greater meaning than what he himself notes of the experience. The sense that Jake is depressed, is seen once in the text after his night out with Georgette and the rest of his friends. At one point in the night, he sees Lady Brett Ashley ushered into a nightclub by a group of men. His reaction to seeing these men is disturbing, as he wishes to lash out violently because of their appearance and identification as homosexuals. This scene whilst problematic, is not the introduction to his wound but the moment that inspires his later acknowledgement of the difficulty it caused him to engage with the woman he loves, Brett. Before this moment, Georgette attempts to stimulate him sexually, but he removes her hand from his pelvic region. In that moment, Georgette asks, "What's the matter? You sick?" to which Jake responds, "Everybody's sick. I'm sick, too" (23). This response demonstrates how he will rationalize his disability throughout the text in contrast to the critics who wish to institute a reading of his 
body and his experience. His proclamation here, like that at the novel's close, is not that everyone is incapacitated but that the ideas of identification were fluctuating. This is not to say that he is supplying the construct of disability, gender, race, and ethnicity as ailments equal in their "ruin" of the established norm, but that the norm was making a claim of its own about the expatriates and veterans.

Jake, as the disabled veteran, closes the novel in the same status as when all his friends have left. He is at peace with himself and his disablement and living an accessible life. He still has his job at the local paper and has two weeks of vacation left. When he receives the telegram from Lady Brett Ashley that leads to his final lines, it is with the inveterate task of finalizing the fact that society is shifting-- and possibly away from the idea of nation-states. His hope was not the reality of the situation, but in that moment, Hemingway creates a person. He shows that there is a capacity for people coming out of the horrors of war to follow their true being and not exist as they are perceived by the nation-state. The disabled veteran is not incapacitated but capable. 


\section{Conclusion}

My conclusion is that nationalism stemmed from patriarchal conditions prior to the war that had already built signifiers to differentiate "others" within society so as to benefit from their labor with a rationale favoring those who gained from that labor. However, the cultural works that attempt to modify these significations, cannot be held fully accountable for the constitution of these conceptions of the nation-state's norms. I noted how Ernest Hemingway and Djuna Barnes took to task the ideas that have been attributed to their work by creating characters and stories that challenged each of these signifiers.

The implication of this research is that the modern world has not always learned from its past and is not necessarily moving toward a more accessible society. The United States' current immigration policy, attempts at repealing the Affordable Care Act, and diminished funding for Planned Parenthood suggest that the current administration's commitment to nationalism is, in fact, a return to values that privilege those who gain most from the labor of "others" at the cost of the identities of those "others." Not perceived to contain any physical product that benefitted the efforts of post-World War I society, these identities were a major concern during the modernist period and stood in direct contrast to social norms.

Readers can make assumptions about what it means to be fully male through Jake's and the Doctor's decisions to pursue a life of wandering about in a Europe that was working to redefine its sensibilities after the First World War. In their respective novels, Jake and Dr. O'Connor are wandering in several European nations that were actively carrying out an imperative to create a unified, masculine 
culture that was capable of standing against the onslaught of total war. The wandering, here, is a figuration of damage. They are referred to as being "lost," carrying feelings of inadequacy and incapacity. The nations they wander in are the cause of their displacement because of the national endeavor to maintain distinctions forcing men and women to be the creators of their own suffering. According to Michel Foucault in Discipline and Punish, "the examination as the...pinning down of each individual in his own particularity... clearly indicates the appearance of a new modality of power in which each individual receives as his status his own individuality, and in which he is linked by his status to his features, the measurements, the gaps, the marks that characterize him and make him a 'case'" (202-3). Therefore, this internalized patriarchy does more to harm the critics who seek to promote an idea that Jake is affected by the forces of dichotomous thought than his resolve to see past his injury and imagine his life as one wherein he can just be another human being. A similar attempt is made by Robin to understand her sexuality and find security in what was considered an ailment at that time.

In the end, Ernest Hemingway and Djuna Barnes understood that disability could not be equated to inability or incapacity. "Disability" and "exile" are labels created by a society to maintain a culture built on nationalist and patriarchal notions of identity. 


\section{Bibliography}

Barker, Clare and Stuart Murray. "Disabling Postcolonialism: Global Disability Cultures and Democratic Criticism." The Disability Studies Reader, 4th ed., edited by Lennard J. Davis. Routledge, Taylor \& Francis Group, 2017, pp. 61-72

Barnes, Djuna. Nightwood. Faber, 2001.

Clare, Eli. Exile \& Pride: Disability, Queerness, and Liberation. Duke University Press, 2009.

Carlston, Erin G. Thinking Fascism: Sapphic Modernism and Fascist Modernity. Stanford University Press, 1998.

Davis, Lennard J. "Introduction: Disability, Normality, and Power." The Disability Studies Reader, 4th ed., edited by Lennard J. Davis. Routledge, Taylor \& Francis Group, 2017, pp.

Davis, Lennard J. "The End of Identity Politics: On Disability as an Unstable Category." The Disability Studies Reader, 4th ed., edited by Lennard J. Davis. Routledge, Taylor \& Francis Group, 2017, pp.

Derrida, Jacques, and Anne Dufourmantelle. Of Hospitality. Stanford University Press, 2000.

Foucault, Michel. Discipline and Punish: The Birth of the Prison. Translated by Alan Sheridan, Random House, 1977.

Fuchs, Miriam. "Dr. Matthew O'Connor: The Unhealthy Healer of Djuna Barnes's Nightwood." Literature and Medicine, Volume 2, pp. 125-134. Johns Hopkins University Press, 1983. https://doi.org/10.1353/lm.2011.0264.

Hemingway, Ernest. A Moveable Feast. Arrow Books, 2011.

Hemingway, Ernest. The Sun Also Rises. Scribner's, 2006.

Kinder, John M. Paying with Their Bodies: American War and the Problem of the Disabled Veteran. The University of Chicago Press, 2016.

Michaels, Walter B. Our America: Nativism, Modernism, and Pluralism. Duke University Press, 1995.

Mitchell, David, and Sharon L. Snyder. Narrative Prosthesis: Disability and the Dependencies of Discourse. University of Michigan Press, 2008. 
Shakespeare, Tom. "The Social Model of Disability." The Disability Studies Reader, 4th ed., edited by Lennard J. Davis. Routledge, Taylor \& Francis Group, 2017, pp. 214-221

Tannen, Deborah. Gender and Discourse. Oxford University Press, 1994.

Thomson, Rosemarie G. "Integrating Disability, Transforming Feminist Theory." The Disability Studies Reader, 4th ed., edited by Lennard J. Davis. Routledge, Taylor \& Francis Group, 2017, pp. 333-351

Tucker, Martin. Literary Exile in the Twentieth Century: an Analysis and Biographical Dictionary. Greenwood Press, 1991. 